\title{
ESTIMATIVE OF CORRELATIONS BETWEEN TIGHTENING TORQUE AND ASSEMBLY FORCE OF BOLTED JOINTS THROUGH MEASUREMENTS AND COMPUTATIONAL SIMULATIONS
}

\author{
João G. Farias ${ }^{1}$, Alex Pizzatto ${ }^{1}$, Vitor Shimada ${ }^{1}$, Thiago Zanotto ${ }^{1}$, Rodrigo Pedroso ${ }^{1}$ e Andre \\ Masetto $^{1}$ \\ ${ }^{1}$ Robert BOSCH Ltda. \\ E-mails: joao.farias@br.bosch.com, alex.pizzatto@br.bosch.com, \\ vitor.shimada@br.bosch.com, thiago.zanotto@br.bosch.com, rodrigo.pedroso@br.bosch.com \\ e andre.masetto@br.bosch.com
}

\begin{abstract}
Experimental tests with axial force and with tightening torque were performed to measure the deformation of bolted joints. From the found curves of force-deformation and torquedeformation, the experimental correlations between tightening torque and assembly force were obtained. The experimental results, together with the guideline VDI2230 [1] for calculation of bolted joints, were used to estimate the material properties and friction coefficients used at finite element numerical model. A full tridimensional model was built, where a rotational angle was applied at bolted joint and the assembly force and tightening torque were calculated. From these output results, the equations that correlate torque and force were estimated. The equations got from the numerical model are in accordance with those obtained experimentally. This way, the numerical model can be used in the future for new studies, without the necessity of new experimental tests.
\end{abstract}

\section{INTRODUCTION}

Bolted joints are widely used on automotive industry to clamped one or more parts. At assembly process, values of tightening torque or angle are normally specified, however, many times, it is necessary to know the axial force value correspondent to the applied torque. On this context, this paper study two bolted joints to estimate the correlations between tightening torque and resultant axial force.

Initially, separated experimental tests with axial forces and tightening torques were performed and the deformation of bolted joints were measured for each load case in order to obtain the correlations between axial force and tightening torque.

The second part of this study was to obtain the correlations through a numerical model by finite element. First of all, the experimental results were used to calibrate the material properties of parts and, together with the VDI2230 [1] to calculate bolted joints, to estimate the friction coefficients of each contact interaction. Then, a full tridimensional model was used to calculate the axial force and tightening torque from the applied tightening angle at bolted joint, and the numerical correlations were obtained. 
Lastly, the experimental and numerical correlations were compared to validate the numerical model, which can be used for future studies of both bolted joints.

\section{BOLTED JOINT GEOMETRIES}

One connection with two bolted joints was used on this study. At one side the connection has interface with an injector body while at other side the interface is with a pipe. Picture 1 shows schematically these bolted joints.

(a) Body Interface

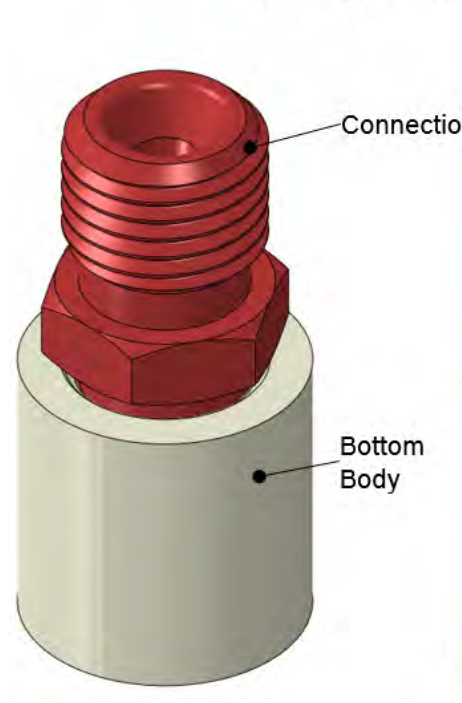

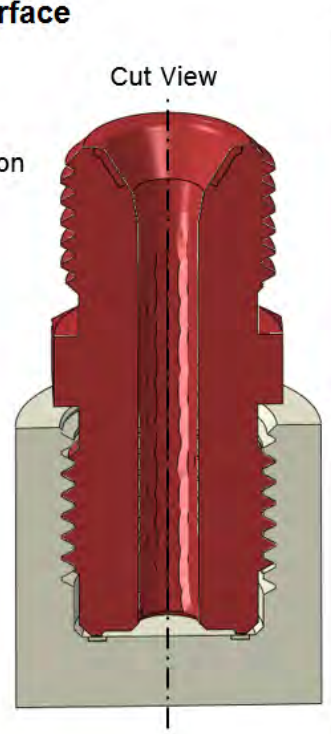

(b) Pipe Interface

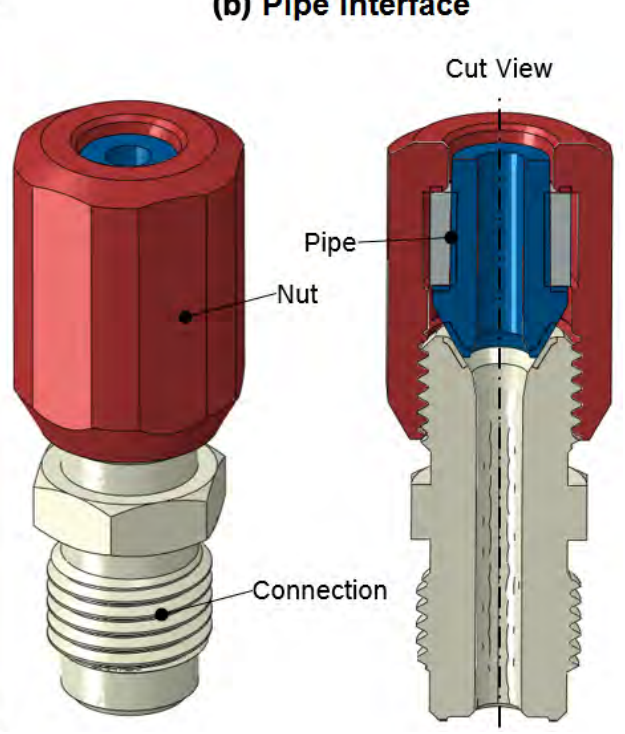

Picture 1 - Bolted joint geometries: (a) body interface and (b) pipe interface.

\section{EXPERIMENTAL TESTS}

\subsection{Bolted joint: body interface}

A device was built to perform experimental tests where axial forces are applied at connections and the deformation of sealing region was measured after each test, as schematically shown in Picture 2. Separately, other experimental tests were performed, using geometries shown in Picture 1(a), applying tightening torques and measuring the same deformation of sealing region. At experimental tests with torques, two different conditions at threads were considered: with oiled threads and with glued threads, in order to evaluate different friction coefficients. 


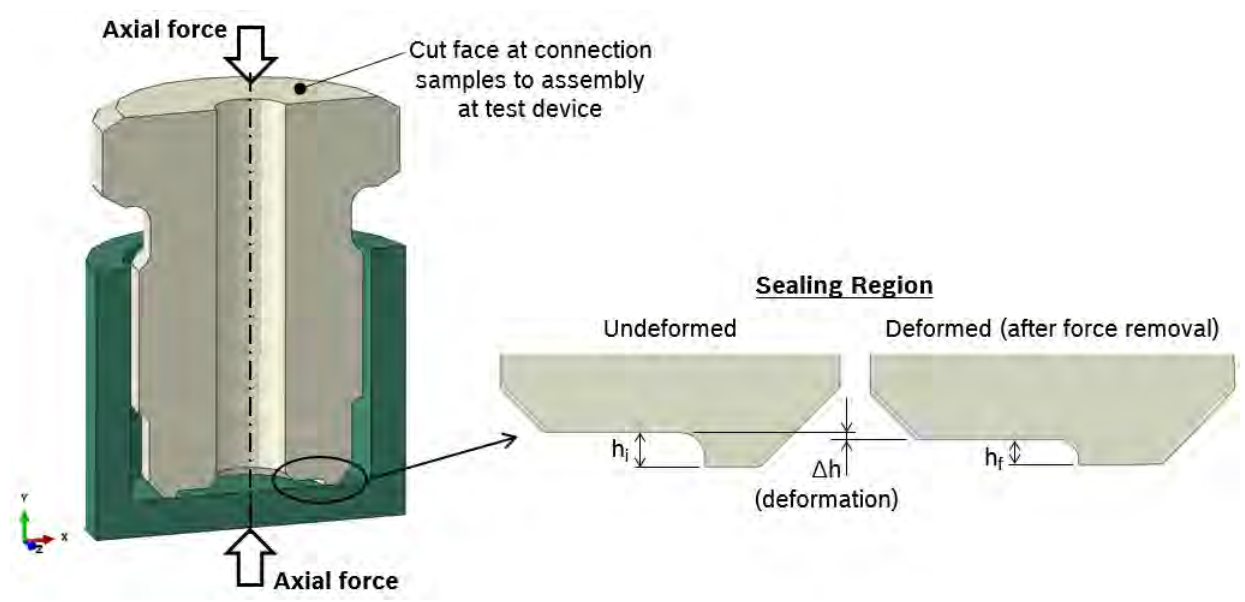

Picture 2 - Axial experimental test of bolted joint with body interface.

\subsection{Bolted joint: pipe interface}

The same procedure was used for the bolted joint with pipe interface. Experimental tests with axial forces and tightening torque are performed separately and, after the tests, the pipe deformations were measured.

\section{NUMERICAL MODELS}

Tridimensional finite element models were built with geometries shown in Picture 1. Dynamic analyses were performed with angular velocity of $15 \mathrm{rpm}$. Linear-elastic material properties were used for all parts, except for the connection, which was used elastic-plastic due to the plastic deformation at sealing region of interface with body. The elastic-plastic material properties of connection were calibrated based on experimental tests with axial force of bolted joint with body interface. The same boundary conditions and loads of tests were set at numerical model and the deformation of sealing region was compared with measurements, as shown in Picture 3.

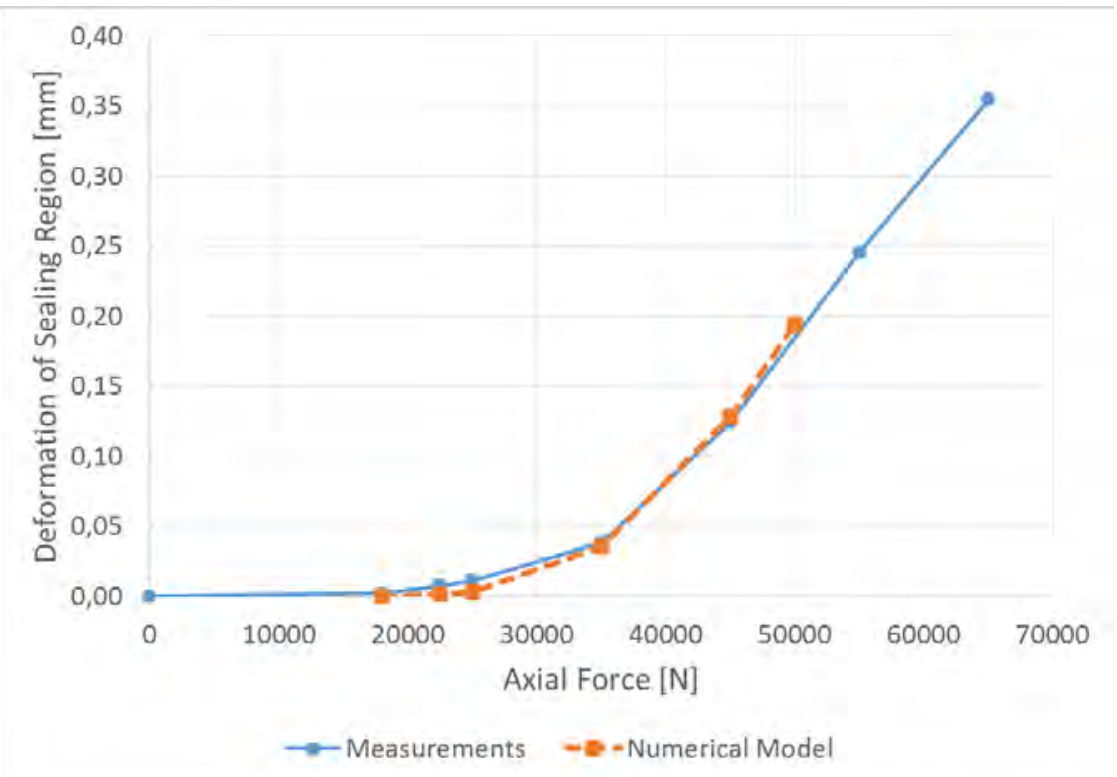

Picture 3 - Comparison between measurements and numerical model for calibration of connection material. 
Friction coefficients were also estimated based on experimental tests results. The correlations between axial forces and tightening torques and the formula

$$
M=F \cdot\left(0,16 \cdot P+\mu_{G} \cdot 0,577 \cdot d_{2}+\frac{D_{k m}}{2} \cdot \mu_{K}\right)
$$

from VDI2230 [1] to calculate bolted joints were used. Where $M$ is tightening torque, $F$ is axial force, $P$ is pitch of thread, $d_{2}$ is pitch diameter of thread, $D_{k m}$ is effective diameter of bolt head, $\mu_{\mathrm{G}}$ and $\mu_{\mathrm{K}}$ are friction coefficients of thread and head respectively.

Considering thread and bolt head geometries and assuming that friction coefficients of threads and bolt heads are equal $\left(\mu_{\mathrm{G}}=\mu_{\mathrm{K}}\right)$ for bolted joint with pipe interface and body interface with oiled thread, mean friction coefficients of 0,18 and 0,13 were calculated respectively. For bolted joint with body interface with glued thread, the mean friction coefficient of head was assumed equal to 0,13 , from case with oiled thread, and of thread was calculated 0,26. Table 1 and Table 2 show the friction coefficient values of each measured point and the mean values of each bolted joint.

Table 1 - Friction coefficients of bolted joint with body interface.

\begin{tabular}{|c|c|c|c|c|}
\hline \multirow[b]{2}{*}{$\begin{array}{l}\text { Tightening } \\
\text { torque [Nm] }\end{array}$} & \multicolumn{2}{|c|}{ Oiled } & \multicolumn{2}{|c|}{ Glued } \\
\hline & $\begin{array}{c}\text { Axial force } \\
{[\mathrm{kN}]}\end{array}$ & $\begin{array}{c}\text { Friction } \\
\text { coefficient [-] }\end{array}$ & $\begin{array}{c}\text { Axial force } \\
{[\mathrm{kN}]}\end{array}$ & $\begin{array}{c}\text { Friction } \\
\text { coefficient [-] }\end{array}$ \\
\hline 60 & 29,7 & 0,15 & - & - \\
\hline 65 & 33,6 & 0,14 & - & - \\
\hline 70 & 36,4 & 0,14 & - & - \\
\hline 75 & 45,8 & 0,11 & 29,0 & 0,23 \\
\hline 90 & 53,2 & 0,12 & 32,9 & 0,25 \\
\hline 100 & 56,8 & 0,13 & 34,8 & 0,27 \\
\hline 110 & 59,8 & 0,13 & 36,6 & 0,29 \\
\hline 150 & - & - & 51,5 & 0,27 \\
\hline & Mean value: & 0,13 & Mean values: & 0,26 \\
\hline
\end{tabular}

Table 2 - Friction coefficients of bolted joint with pipe interface.

\begin{tabular}{|c|c|c|}
\hline \multirow{2}{*}{$\begin{array}{c}\text { Tightening } \\
\text { torque }[\mathrm{Nm}]\end{array}$} & $\begin{array}{c}|c| \\
\text { Axial force } \\
{[\mathrm{kN}]}\end{array}$ & $\begin{array}{c}\text { Friction } \\
\text { coefficient [-] }\end{array}$ \\
\hline 60 & 25,0 & 0,17 \\
\hline 70 & 27,7 & 0,18 \\
\hline 80 & 27,8 & 0,20 \\
\hline & Mean value: & 0,18 \\
\hline
\end{tabular}

Picture 4 shows boundary conditions and loads of each numerical model. Tightening angles were applied and axial forces and tightening torques were calculated to obtain the correlation between them. 
(a) Body Interface

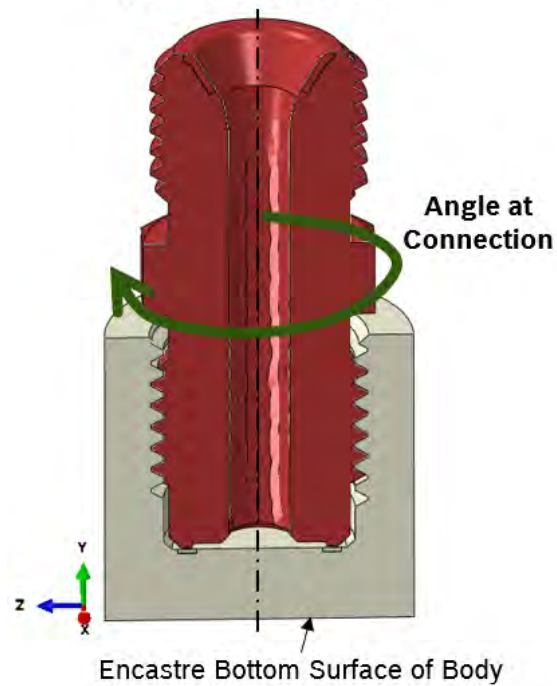

(b) Pipe Interface

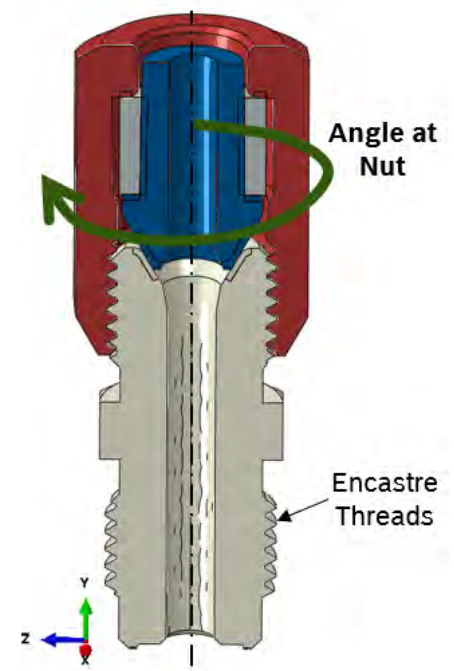

Picture 4 - Numerical models: (a) bolted joint with body interface and (b) bolted joint with pipe interface.

\section{RESULTS}

\subsection{Experimental tests}

Picture 5 shows the results of experimental tests with axial forces and tightening torques and also the correlation between them based on deformation of sealing region for bolted joint with body interface. From axial experimental tests, it is possible to verify the axial force limit of approximately $18 \mathrm{kN}$ to begin plastic deformation at sealing region. From tightening torque experimental test, it is possible to see the difference between samples with oiled and glued threads. As expected, for the same deformation it is necessary higher torque with glued threads than oiled. Regarding the correlation between axial force and tightening torque, linear correlations are observed at both oiled and glued cases. 

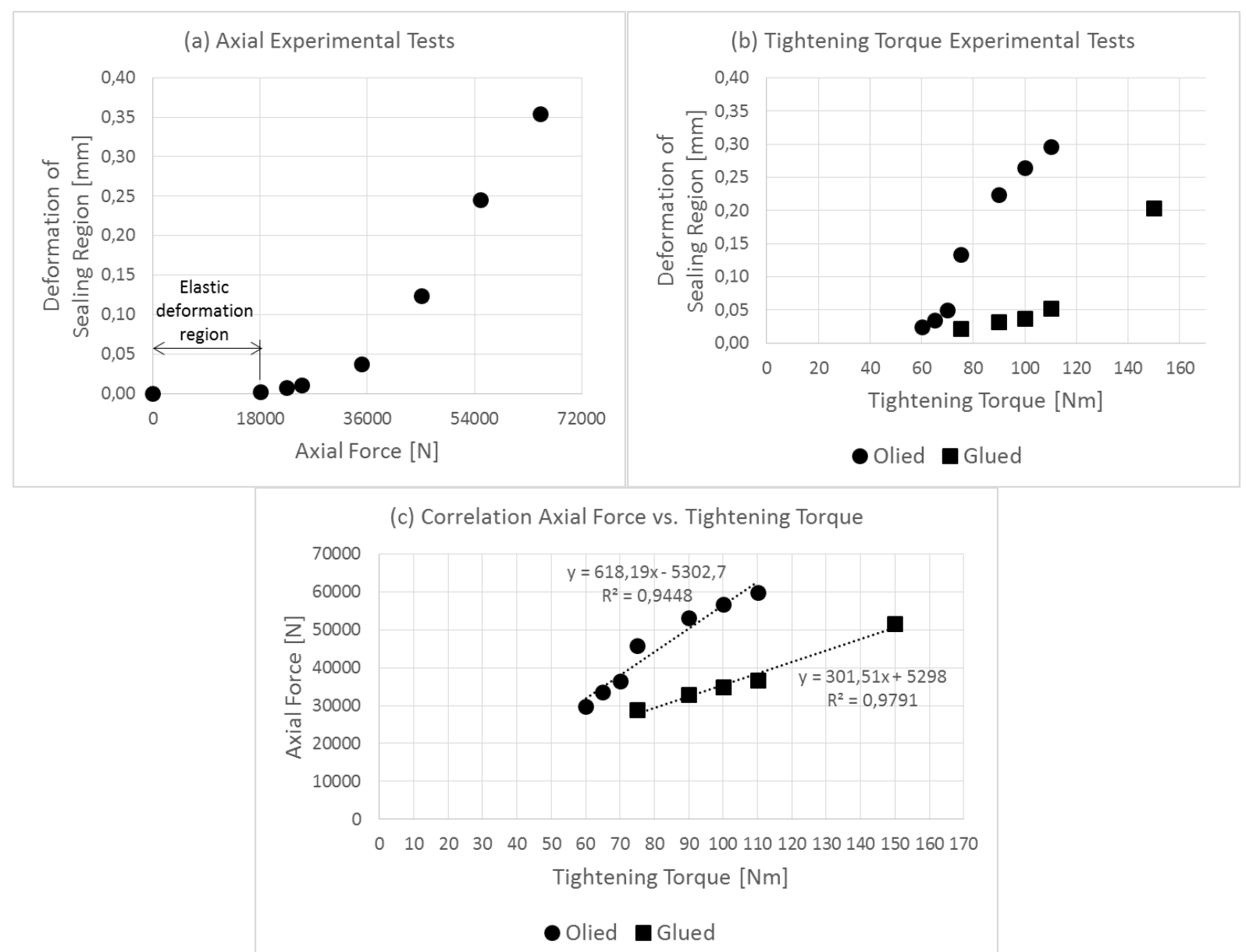

Picture 5 - Results of experimental tests of bolted joint with body interface: (a) axial force tests, (b) tightening torque testes with oiled and glued threads and (c) correlations between axial force and tightening torque.

For bolted joint with pipe interface, the results of experimental tests and the linear correlation between axial force and tightening torque are shown in Picture 6. The axial force and tightening torque limits to begin plastic deformation at pipe are approximately $25 \mathrm{kN}$ and $60 \mathrm{Nm}$ respectively. In this case, forces and torques are not evaluated much higher than limit for plastic deformation because the elastic region is desired at current connection application. 

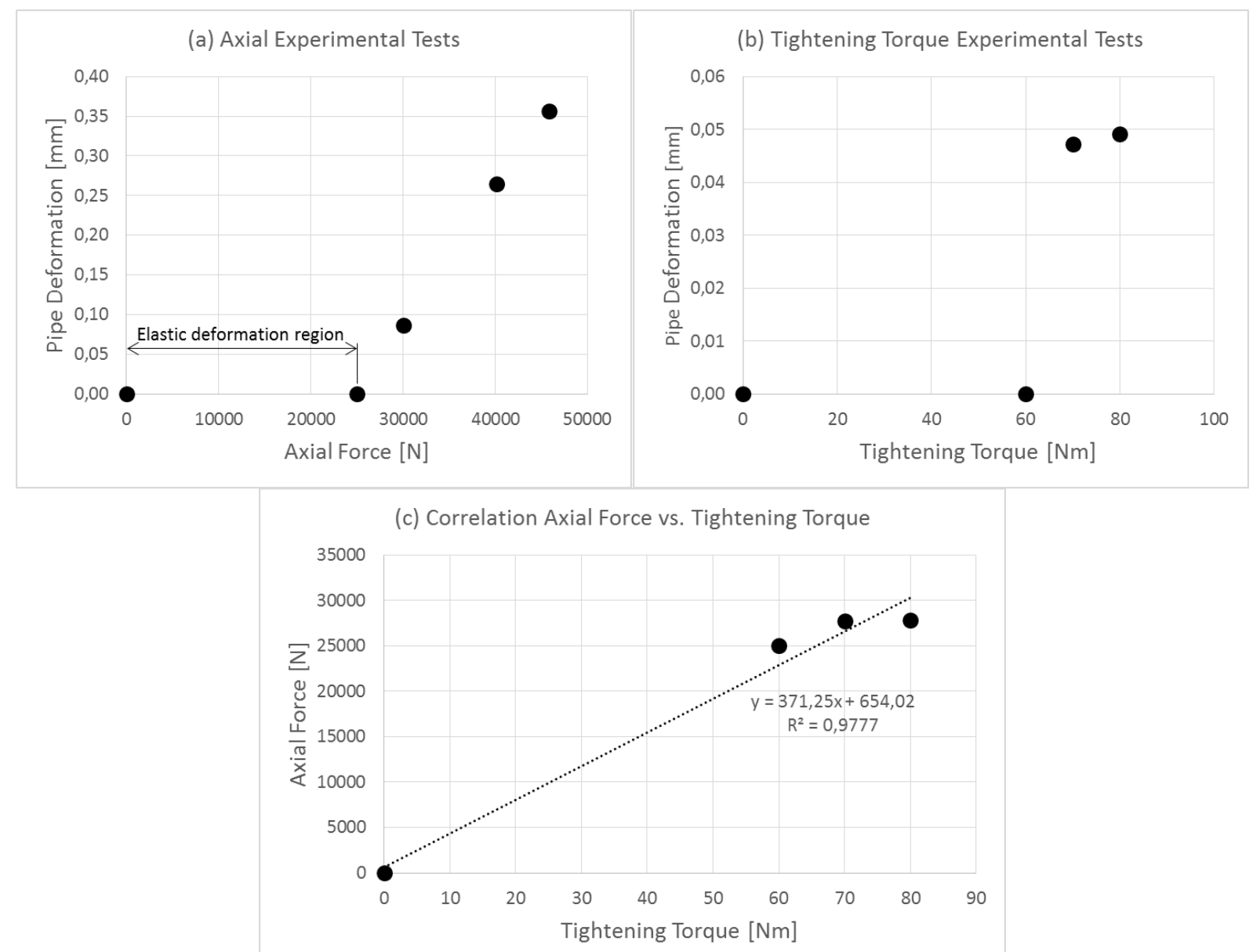

Picture 6 - Results of experimental tests of bolted joint with pipe interface: (a) axial force tests, (b) tightening torque testes and (c) correlation between axial force and tightening torque.

\subsection{Numerical Models}

Picture 7 shows axial force and tightening torque as function of tightening angle for bolted joint with body interface at models with oiled and glued threads. As expected, under same tightening angle, model with glued thread has higher resultant tightening torque than model with oiled thread. This behavior is not observed for axial force, where both models have same axial force under same angle. Consistent with measurements, numerical models show linear-elastic behavior up to approximately $18 \mathrm{kN}$ or tightening angle of $6^{\circ}$. Linear correlations between axial forces and tightening torques are also shown in Picture 7. 


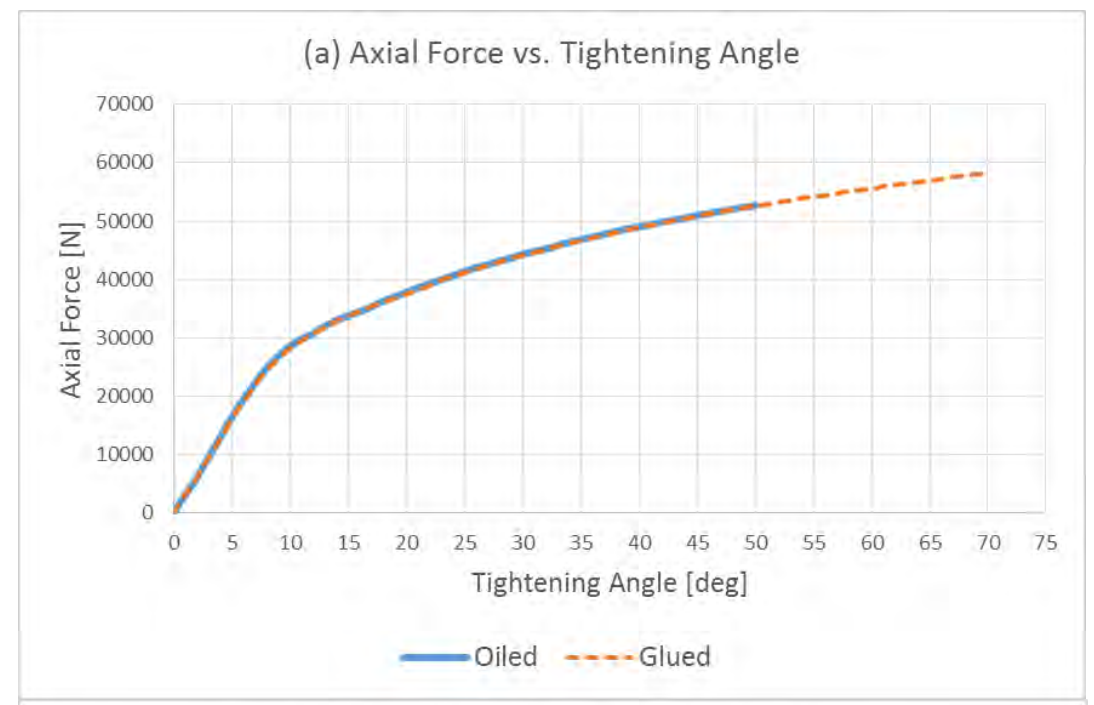

(b) Tightening Torque vs. Tightening Angle
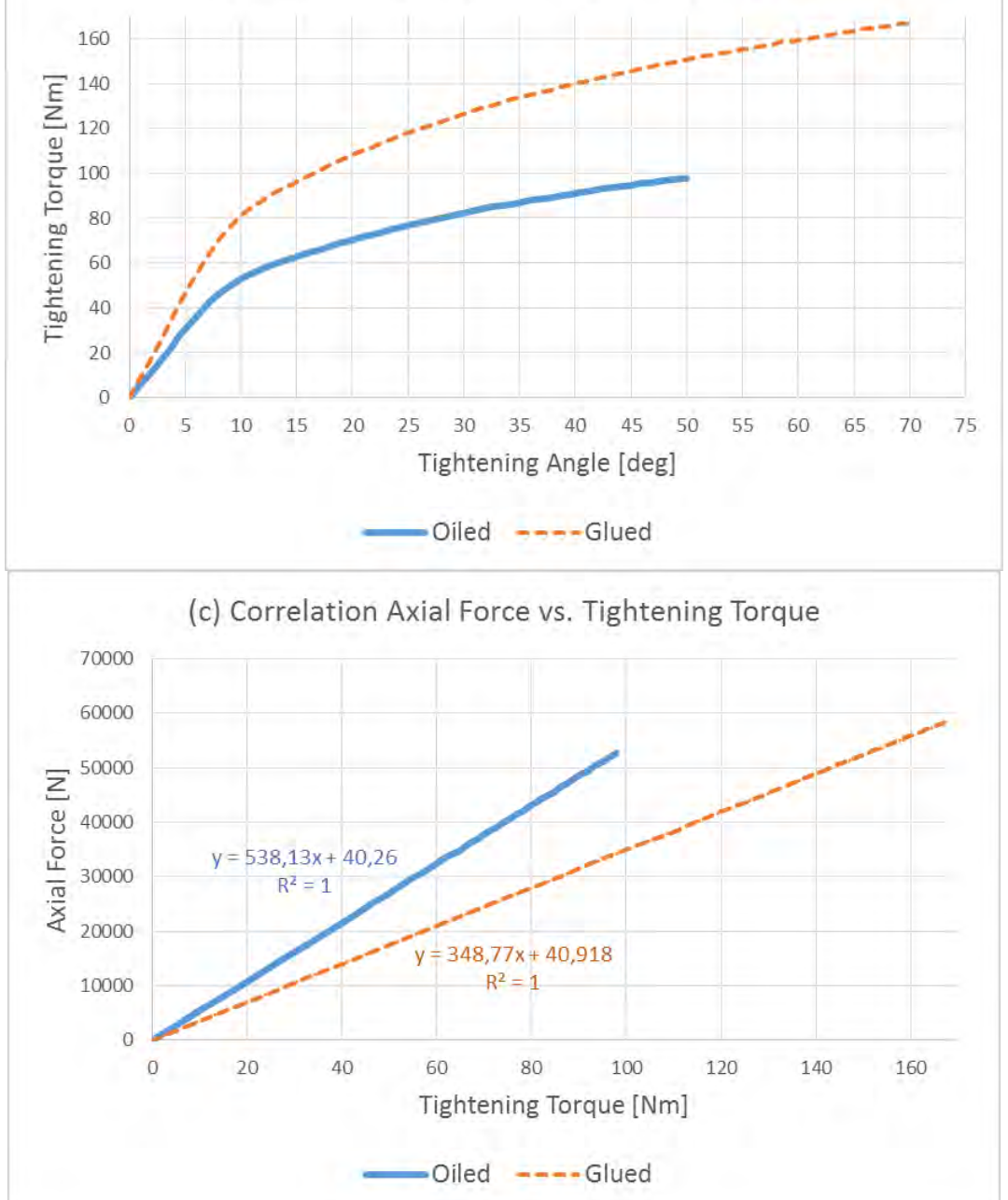

Picture 7 - Results of numerical mode of bolted joint with body interface: (a) axial force vs. tightening angle, (b) tightening torque vs. tightening angle with oiled and glued threads and (c) correlations between axial force and tightening torque.

The same results are obtained for bolted joint with pipe interface, as shown in Picture 8. In this case, the numerical model was performed only at linear-elastic region, in accordance to 
current application, with axial force and tightening torque limits of approximately $24,4 \mathrm{kN}$ and $60 \mathrm{Nm}$, consistent with measurements.
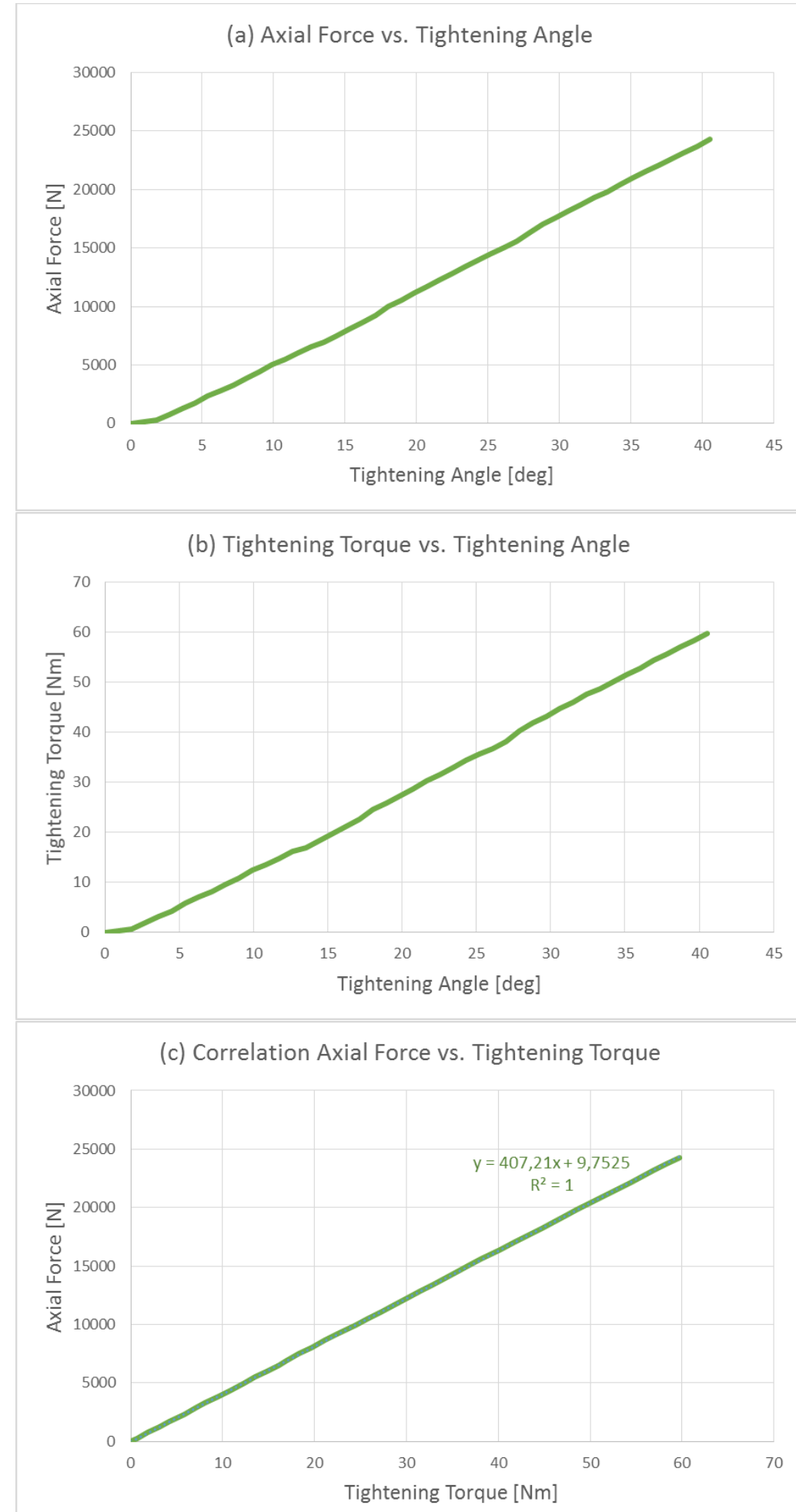

Picture 8 - Results of numerical mode of bolted joint with pipe interface: (a) axial force vs. tightening angle, (b) tightening torque vs. tightening angle and (c) correlations between axial force and tightening torque. 
4.3. Comparison between experimental tests and numerical models

With results from experimental tests and numerical models, they were compared in order to validate the numerical approach. At both bolted joints with body and pipe interfaces, the comparison is satisfactory, as shown in Picture 9.

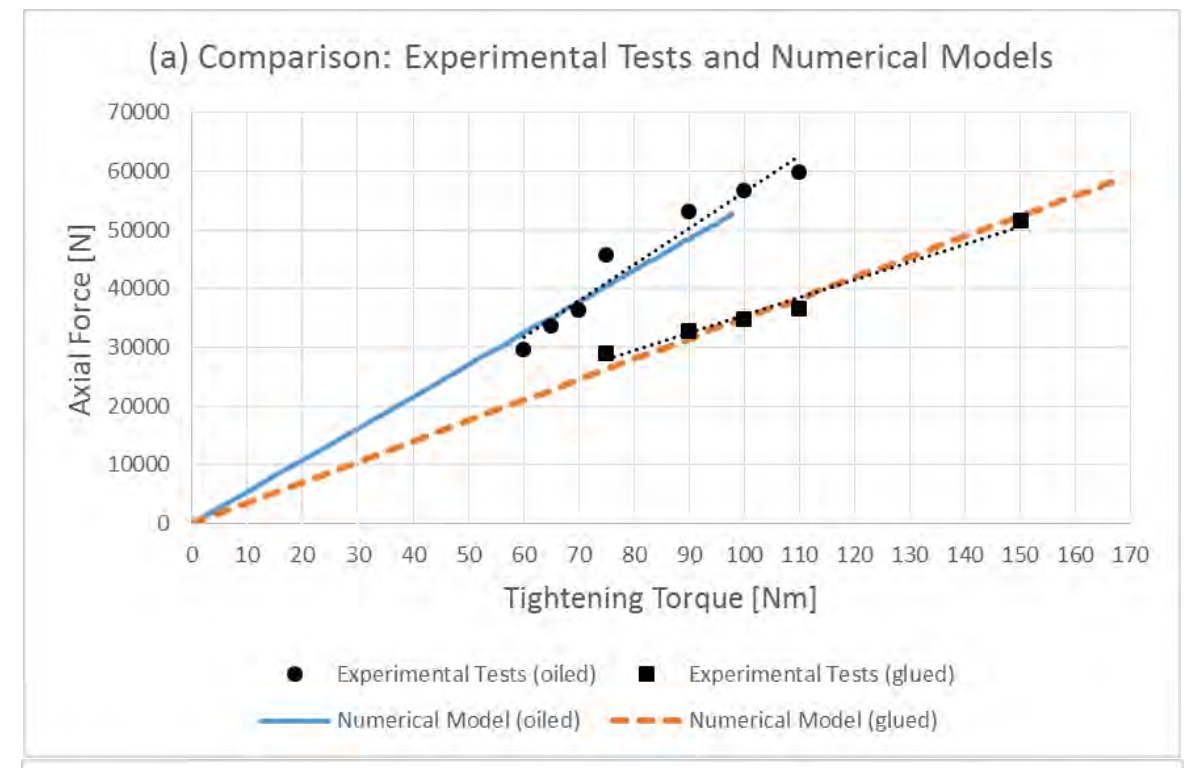

(b) Comparison: Experimental Tests and Numerical Model

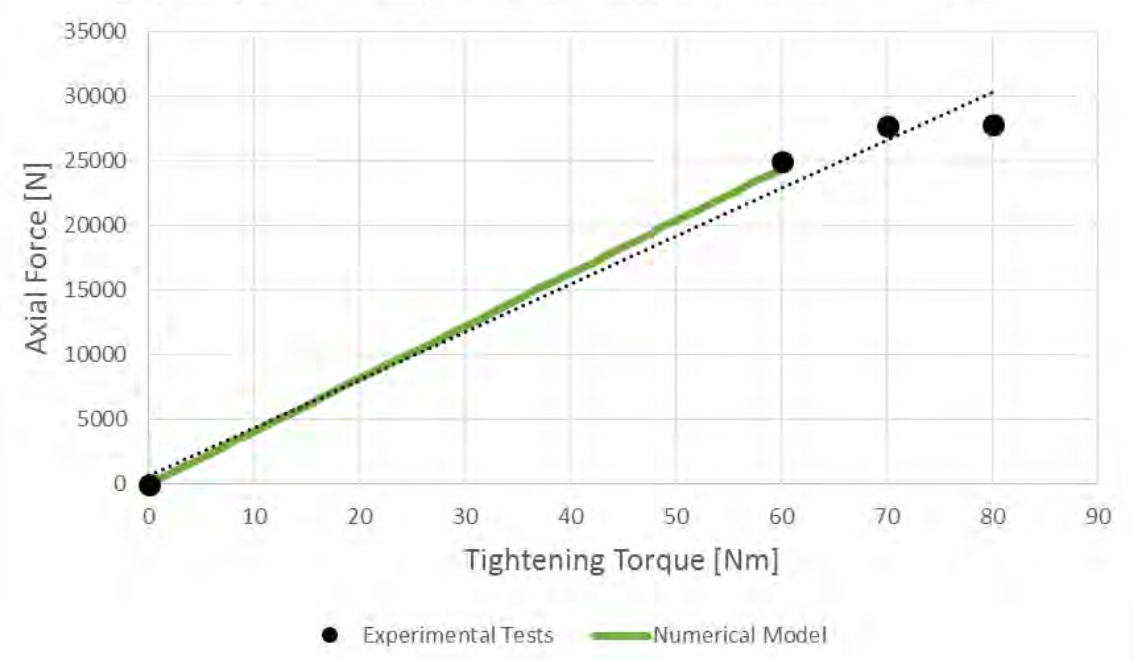

Picture 9 - Comparison between experimental tests and numerical models: (a) bolted joint with body interface with oiled and glued threads and (b) bolted joint with pipe interface.

\section{CONCLUSIONS}

Numerical results are in accordance to experimental tests. The limits between elastic and plastic deformation regions are similar and the correlations between axial forces and tightening torques are consistent. 
The linear equation from numerical models can be used to estimate the axial force from an applied tightening torque. For bolted joint with body interface with oiled thread, the equation is

and with glued thread is

$$
F=538,1 \cdot M+40,3 \quad \text { Eq. } 2
$$

$$
F=348,8 . M+40,9 \text {. } \quad \text { Eq. } 3
$$

For bolted joint with pipe interface, the equation is

$$
F=407,2 \cdot M+9,7 . \quad \text { Eq. } 4
$$

Based on good agreement between numerical models and experimental tests, the numerical model is validated and it can be used for future studies, without the necessity of built physical samples and perform new experimental tests. As well as this work methodology can be used to generate numerical models of bolted joints to subsequent analyses, optimizations and rapid deviation resolutions.

\section{REFERENCES}

[1] VDI2230. Systematic calculation of high duty bolted joints. Joints with one cylindrical bolt. 2003. 